\title{
A Preliminary Study of Motor Ability
}

\section{John A. Hancock}

To cite this article: John A. Hancock (1894) A Preliminary Study of Motor Ability, The Pedagogical Seminary, 3:1, 9-29, DOI: 10.1080/08919402.1894.10534794

To link to this article: http://dx.doi.org/10.1080/08919402.1894.10534794

册 Published online: 31 Aug 2012.

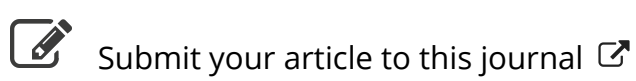

LII Article views: 1

Q View related articles $\asymp$

4 Citing articles: 5 View citing articles 


\title{
A PRELIMINARY STUDY OF MOTOR ABILITY.
}

\author{
By John A. Hancock, \\ Fellow in Pedagogy, Clark University.
}

The enormous difference in ability between the child and the adult, both physically and mentally, is fully realized by few. While it is commonplace to say that there is such a difference, yet the practice of the school makes comparatively little allowance for it. Pedagogy is based on the psychology of the adult mind, and the conditions of school-room work are generally adapted to the adult. It is obvious that instruction and discipline should be adjusted to the mental and physical stages of development of children; and that we need to know just what the ability of children of each age is in order to plan a fitting course of education.

The following investigation was begun for the purpose of finding what movements children can best make; to learn something more definite of the relative ability of child ren and adults, and of the relation between development and decline of motor ability; and also in the hope of finding simple tests for incipient nervous diseases.

\section{I.}

In directing the work of a body of teachers in the field of child study, the writer compiled the following circular. It served in his own investigations, of which this paper is a preliminary report :-

\section{THE MOTOR ABILITY OF CHILDREN.}

Very little study has been made of the motor ability of children. It is probable that we could teach many of the subjects of the common schools better if we knew just what movements children can make. Kindergarten training would also be placed on a more satisfactory basis.

Preyer has shown that children in learning to talk have the same difficulties as people who have diseases of speech.

Peculiar movements, such as dragging the feet, trembling of the hands or head in adults, are symptoms of certain diseases of the muscles and nerves. It will be of interest to determine whether in the normal growth of children such movements do not also appear. 
It has been suggested that certain nervous diseases of children begin while they are yet able to attend school, and that by simple tests, cases of such diseases may be determined during their school stage.

To aid in solving these problems the following tests have been gathered from various sources, and are now offered for trial and criticism.

In testing pupils take two or three of them at a time, before or after school, noting which time. Record age, sex and nationality. Use but one syllabus at a time - the other some days later. If it should seem best to you, omit any one of the tests. If the pupil shows signs of fatigue, do not continue testing him. Give absolutely no help other than indicated in the directions, for results obtained can not show in any way the value of your teaching. The most insignificant looking paper is often, to the expert, the most valuable; so make no effort to make your returns "show up well." Number your resulte to correspond with the tests.

\section{Firgt Serieg.}

1. 'Aak the child to stand with feet close together and hands at sides. Is there any swaying of the body? Try same with eyes closed. What difference?

2. Have him walk acrose the room backwards with eyes closed. (Keep near him to prevent falling.) Is there any dragging of either toot, walking with feet wide apart, or turning to right or left ?

3. Have him try to sit still a half minute exaotly. Note all the movements he makes in the effort. Does he hold his breath ?

4. Ask him to close his eyes and hold his hands out horizontally with the fingers spread. Is there tremor or twitching of the fingere? Which ones and in what directions? Is it slight or distinct?

5. Hold your hands above your head out of sight and with palms front. Ask him to do the same. Does he raise them to the same height? Hold them symmetrically? Are the fingers or thumbs epread apart on either hand? Which? Which hand sinks first on a half-minute's trial? Hold up your own hands but a moment.

6. Place bim ten feet away. Toss back and forth ten times a ball as large as a tennis ball. How and where does he throw it? How many times does he catch it?

7. Ask the boys to lie down on their backs, if they are willing. How do they get up? Have they difficulty ?

8. Ask for the pronunciation of these letters and words and note errors: $r, l, s, t, k, d, f, n, v, y$, go, which, thin, the, long, show.

9. What signs of mental fatigue have you noticed in him in school work? Has he made any involuntary movements during these tests?

10. Please add any comments or suggestions that may occur to you.

\section{SECOND SERTEA.}

1. Does the child dress himself? Button his clothing, and fasten hooks and eyes?

2. Can he tie the ends of a string together? In what kind of a knot?

\footnotetext{
'The swaying may be charted exactly and easily; if desired, directions will be given.
} 
3. Can he thread a needle? How small a one? In which hand does he hold it ?

4. Can he interlace slats? Interlace four and six before him? See patterns on $\theta$ and two. Does he even copy the pattern?

5. Can he wind thread on a spool? How does he do it?

6. Can he spin a top made of half a spool or button mold? Can he snap a marble?

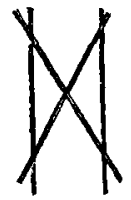

FIg. 1.

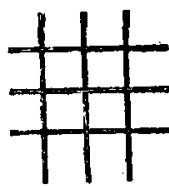

Fra. 2.

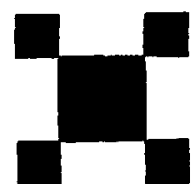

Fis. 8.

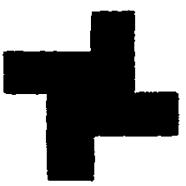

Fra. 4

7. Can he hop on each foot? Stand on tip-toes or heels? Touch his knees or shoes while standing ?

8. Place before him pattern number three; give him squares of paper or square blocks; ask him to imitate it. Then show him number four. Does he shift the outer blocks of number three to make the other figure, or does he build anew from the beginning? The patterns may be shown him drawn full size on paper, or made of the blocks. If he fails, divide each pattern vertically in the middle; try him and note results.

9. Count and beat time, double, treble and quadruple. Can he do it ? Rapidly?

10. Does he swing his arms or sway his body when walking? Oan he march, keeping step as you count time or play for him? Can he run and keep time? Does he, when marching, move the head, eyes, mouth or tongue?

11. Pat the top of your head and at the same time move the other hand in a circle on the breast. Can he imitate you ?

12. Rest your fore-arms on the table, the hands in an easy position with the fingers curved, and the lower parts of the palms and the tips of the fingers touching the surface of the table. Begin tapping, letting the movements proceed rapidly from the little fingers to the thumbs. Ask him to imitate you. Notioe the movements he actually makes. Are they with the hand and arm moving together from the elbow; the whole hand moving from the wrist; all of the fingers moving in unison from the knuckles; or with index finger alternating with the other three? Reverse the tapping, beginning with the thumbs. Can he imitate you any better? Just what does he do ?

13. Can he drive a nail, or hit it squarely after several trials when started for him?

14. Can he roll a hoop? Skate? Turn a somersault or walk on his hands? (The boy, of course.)

15. What movements seem to you to be most diffoult for children to learn?

Bibliography. The following bear on the motor ability of children and are among the best that have been written:

Preyer. Development of the Intellect. D. Appleton \& Oo., N. Y., 1890.

SlaCK. Mirror Writing and Left-Handedness. PED. SEM., Vol. II. No. 3. 
Crichton-Brown. The Nervous System and Education. $J$. and A. Churchill, London.

Clouston. The Neuroses of Development. Oliver and Boyd, Edinburgh, 1892.

WARNER. Mental Faculty. MeMillan \& Co., New York, 1890.

WARNER. Muscular Movement in Man. Journal of Mental Science, 1889.

WARNER. The Children and How to Study Them. Kegan, Paul \& Co., London.

RICH'CER. Levana. Bell \& Sons, London, 1889.

BRYan. Development of Voluntary Motor Ability. Journal of Pyych., Vol. V. No. 2.

Burnham. A Scheme of Classification for Child Study. Ped. SEM., Vol. II. No. 2.

Barnes. Children's Drawings. Ped. Sem., Vol. II. No. 3.

MAGNUS. Industrial Education. Kegan, Paul \& Co., London, 1888.

WOODWARD. The Manual Training School. D. C. Heath \& Co., Boston, 1887.

SuUYs. Manual Training in Elementary Schools for Boys. Industrial Ed. Ass'n, New York.

Belfield. Manual Training and Public Schools. Industrial Ed. Ass'n, New York.

MCARTHUR. Education in its Relation to Manual Industry. D. Appleton \& Co., New York.

One hundred and ten of the children tested are in the public schools of Worcester, fifteen are in a Catholic orphanage, and the remainder in a parochial school. The ages of the children are five, six, and seven. All were in the first year of school work. The children in the orphanage, though mainly from the homes of the very poor, were well cared for. One of the public schools uses a modification of the kindergarten work in connection with the usual primary work. No rejection of any child was made except when over seven years of age.

Previous to beginning work, the school was visited and an effort made to become acquainted with the children. The children were told that no one need be tested unless willing. In three cases children refused, but later came voluntarily and asked to be tested.

At the outset the work was found to be fatiguing to the children. It was accordingly divided into three parts and the round of the school taken with each.

The experiments had in large part to be made in hallways, but this did not seem to make any difference. City children, like their elders, pass and repass people many times each day and pay no attention to them. Rarely was head or eye turned to chance passers.

Two children were sent out at a time. Generally one or more teachers were present as weil. At one school also, a boy was present " who, for being good and working hard," was permitted to come out and see the "machine;" and twice a 
girl from a higher grade, who came down stairs "with the nose-bleed," spent two hours in "helping."

In the effort to train the intellect of the child, considerable quiet is demanded of him. It is one of the "faults" of children, in the minds of many teachers and parents, that they do not keep as quiet as the adult. The quiet child who sits through the sermon, or who sits still when callers are present, and who does not tear or soil its clothing, is liked and given the reputation of being good.

With the purpose of studying the ability of children to keep quiet, the first test was devised. The apparatus used is known as the ataxiagraph. (1) It consists of an upright support, to which is attached an adjustable arm about two feet long. At its extremity is attached a large cork. A small glass tube passes through it. Within the tube, working up and down, is a glass rod about six inches long, and drawn to a point at its lower end. On the upper end is attached small cork to keep the rod from falling through. A piece of smoked paper is pasted to a glass plate, four by five inches, at the edges. The plate is then ready to attach to a cap. This should be a flat-topped one with a rubber band, under which the plate can be secured at one edge. After the tracing is taken, the plate is removed, the paper cut off, and given a bath in shellac and dried.

Since it appeared that the position taken by the subject required the coördination of a large number of the largest muscles of the body, this test would show something of the control of them. The child was asked to stand with feet close together and hands at sides, to keep his attention on a distant object, and to try to stand still for a minute. After this was done he had a half minute or more of rest, when the test was repeated with eyes closed. Specimen tracings for men and children under similar conditions are given.

No device was available for measuring the amount of movement exactly. It is in almost every case very much greater for children than for men. The rectangles which would just contain these tracings in the anterio-posterior and lateral directions were measured. In thirty cases the tracings were repeated at a later date without material difference in the rectangles, and with fully as miscellaneous movement.

Bullard and Brackett $\left({ }^{2}\right)$ studied the swayings of 150 men who were between the ages of twenty and thirty. They were competing in a physical examination and were all in good health. They were tested for a half minute only. As this fact was not learned till the tests on the children were well under way, a number of tests were made on men for a whole minute, but without material variation from the averages of 
the 150. These averages found by Bullard and Brackett were, with eyes closed, $3.764 \mathrm{~cm}$. in the anterio-posterior direction by $1.951 \mathrm{~cm}$. laterally; with eyes open, $3.475 \mathrm{~cm}$. by $1.963 \mathrm{~cm}$. Hinsdale ( ${ }^{\mathrm{s}}$ ) found that normally the anterioposterior measurement was one-third to one and one-half inches, and that swaying generally increased when eyes were closed. His tests were for a minute. He had but twelve subjects-young men in good health. The arerage measurement of these men was $2.55 \mathrm{~cm}$. by $2.1 \mathrm{~cm}$.

He found ataxic cases to sway from $5.7 \mathrm{~cm}$. to $7.0 \mathrm{~cm}$. in anterio-posterior direction by $6.35 \mathrm{~cm}$. to $8.2 \mathrm{~cm}$. laterally.

He measured, also, ten cases of chorea. The anterio-posterior average was $2.35 \mathrm{in} .(5.5 \mathrm{~cm}$.$) ; the lateral average,$ 1.45 in. ( $3.7 \mathrm{~cm}$.$) .$

The averages in my own tests are as follows :

\section{EYES OPEN.}

Eyes Closed.

35 boys, 5 years old, $5.8000 \mathrm{~cm}$. by $5.2228 \mathrm{~cm}$; $6.6810 \mathrm{~cm}$. by $5.7675 \mathrm{~cm}$. 22 girls, 5 years old, $5.7773 \mathrm{~cm}$. by $4.9600 \mathrm{~cm}$.; $5.5400 \mathrm{~cm}$. by $5.0954 \mathrm{~cm}$. 47 boys, 6 years old, $5.1148 \mathrm{~cm}$. by $4.2660 \mathrm{~cm}$; $5.6957 \mathrm{~cm}$. by $5.1637 \mathrm{~cm}$. 18 girls, 6 years old, $5.0611 \mathrm{~cm}$. by $3.7277 \mathrm{~cm}$; $5.6000 \mathrm{~cm}$. by $4.3333 \mathrm{~cm}$. 23 boys, 7 years old, $4.9608 \mathrm{~cm}$. by $4.2434 \mathrm{~cm}$.; $6.0086 \mathrm{~cm}$. by $5.4521 \mathrm{~cm}$. 13 girls, 7 yeare old, $3.9538 \mathrm{~cm}$. by $3.2769 \mathrm{~cm}$.; $4.8230 \mathrm{~cm}$. by $3.7615 \mathrm{~cm}$.

One hundred and ten were steadier with the eyes open than with them shut; forty-eight, with eyes closed; in two cases there was no difference. The child being shorter, would sway less than the man, were other conditions the same. In point of fact there is a significant difference in the other direction.

With eyes open there is an increase of control in each year. The girls are steadier than the boys. Both of these facts were to be expected, since girls mature earlier than boys; jet if the number of subjects was larger, and equal for each sex, a different result might be found.

During these tests frequent twitchings of the fingers were observed in a large majority. Out of this and the many other involuntary movements came the suggestion to try the steadiness of shoulder and finger, and so to get some comparative results for control of large and small muscles.

The instrument named by Jastrow the automatograph was used. It is described by him as follows : (4) "There is first a piece of plate glass, fifteen inches square, resting on a stout wooden frame; this frame is mounted on three adjustable brass legs, raising it an inch or so from the table. By means of the screw adjustment of the legs, the plate glass is brought into exact level. Three brass balls, which must be very perfectly turned and polished spheres, about three-fourths of an inch in diameter, are placed in the form of a triangle upon 
the plate; upon these balls rests a very light wooden frame. The recording of the movement is equally simple." 'To the light frame is attached a slender rod about six inches long, bearing at its end a device the same as used to mark the movement in the ataxiagraph. A screen is used to prevent the subject from seeing the record.

No tests so far as known having been made for this particular purpose, trials were first made on twenty-five of the Clark University men. The subject was seated with back supported, the hand and forearm resting with palms downward on the instrument, the elbow slightly flexed, in order that no strain might be brought on the muscles controlling it. The position admits of free lateral movement of the shoulder and of very little in a direction perpendicular to the body. The subject was asked to hold his arm still for a minute. He was told to do this as he looked at his hand. After an interval of a half-minute or more for rest, the test was repeated with the eyes closed. The averages for both men and children are as follows :

Eyes OPEN.

Exes Closed.

Perpendicular movement.

Lateral. Perpendicular movement. Lateral.

$25 \mathrm{men}, \quad .242 \mathrm{~cm}$. by $.752 \mathrm{~cm}$.; $.156 \mathrm{~cm}$. by $1.460 \mathrm{~cm}$. 18 boys, 5 years old, $.816 \mathrm{~cm}$. by $3.400 \mathrm{~cm}$; $1.027 \mathrm{~cm}$. by $4.916 \mathrm{~cm}$. 15 girls, 5 years old, $.833 \mathrm{~cm}$. by $3.940 \mathrm{~cm}$; $.780 \mathrm{~cm}$. by $4.706 \mathrm{~cm}$. 34 boys, 6 years old, $1.191 \mathrm{~cm}$. by $4.258 \mathrm{~cm}$; $.805 \mathrm{~cm}$. by $5.058 \mathrm{~cm}$. 12 girls, 6 years old, $.433 \mathrm{~cm}$. by $3.883 \mathrm{~cm}$; $1.825 \mathrm{~cm}$. by $4.166 \mathrm{~cm}$. 14 boys, 7 years old, $.600 \mathrm{~cm}$. by $3.750 \mathrm{~cm}$; $.428 \mathrm{~cm}$. by $5.207 \mathrm{~cm}$. 10 girls, 7 years old, $.410 \mathrm{~cm}$. by $3.580 \mathrm{~cm}$; $.480 \mathrm{~cm}$. by $3.550 \mathrm{~cm}$.

The relative difference in the control of child and man here is greater. The rectangles are smaller because the levers are shorter, for one thing. The measurements in the case of the children are unsatisfactory so far as the perpendicular movement is concerned. The difficulty of keeping the children from moving the body, although it was well supported, was so great that this measurement is of little value as a test of control of shoulder movement. The breathing also, influenced it more than it did the lateral movement. Recesses in all the schools were so short that the chances for active play unsettling the steadiness of the muscles were very slight.

Bullard and Brackett ( ${ }^{5}$ ) used in testing the control of the entire arm an instrument known as the tremograph. It is described by them as follows : "It consists essentially of a long, light wooden rod, which runs through a closely fitting brass cylinder so hung in a vertical compass joint on the top of a firm upright as to permit of movement both vertically and horizontally in all directions. One end of the rod is fur- 
nished with a thimble, or some other contrivance, for holding the finger, while to the other is attached a Pflüger's pen. Various weights are attached to the rod in order perfectly to balance it. The upright, made of brass, is placed in the centre of a rectangular wooden platform with low grooved sides, into which it fits closely. At one end of this platform is a transverse groove. This groove serves to hold the glass plate, over which the paper for the tracings is stretched, while the board supports it behind."

The subjects sat with back supported, the forearm and hand resting on the table, palm of hand downward with tip of finger resting in the thimble, the thumb and other fingers so placed that no strain or effort should be felt in them. Early in the work, the fact developed that children could not hold their attention for a whole minute on the index finger as requested. No amount of persuasion availed. After a half-minute, and sometimes before, all control of the finger seemed lost, hence the finger tests were all made for a half-minute on both men and children. Control of the muscles and attention seem to me to be too closely associated in young children to permit study of either separately.

The instrument multiplies the movement four times; the results are reduced accordingly. The same university men gave tracings for this test. The following are the results : -

With Eyes OPEN.

Verticai movement. Lateral.

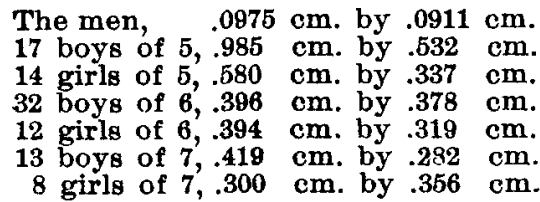

Eyes Closed.

Vertical movement. Lateral. $.085 \mathrm{~cm}$. by $.110 \mathrm{~cm}$. $.794 \mathrm{~cm}$. by $.680 \mathrm{~cm}$. $.714 \mathrm{~cm}$. by $.453 \mathrm{~cm}$. $.689 \mathrm{~cm}$. by $.534 \mathrm{~cm}$. $.535 \mathrm{~cm}$. by $.395 \mathrm{~cm}$. $.693 \mathrm{~cm}$. by $.442 \mathrm{~cm}$. $.312 \mathrm{~cm}$. by $.365 \mathrm{~cm}$.

The same general relations hold in this table as in the others.

Reckoned in terms of the nearest centimeter, the anterioposterior swayings of men and children are as follows :-

\begin{tabular}{rrr|r|r|r|r|r|r|r|r|r|r|r}
\hline \hline CM. & & 0 & 1 & 2 & 3 & 4 & 5 & 8 & 7 & 8 & 9 & 10 \\
\hline 150 men . . . & 1 & 20 & 37 & 48 & 25 & 11 & 9 & 6 & 2 & 1 & 0 \\
Children . . . & 0 & 16 & 1 & 11 & 31 & 45 & 35 & 13 & 13 & 7 & 2 \\
\hline
\end{tabular}

The following will show the ranges in lateral control for the shoulder :- 


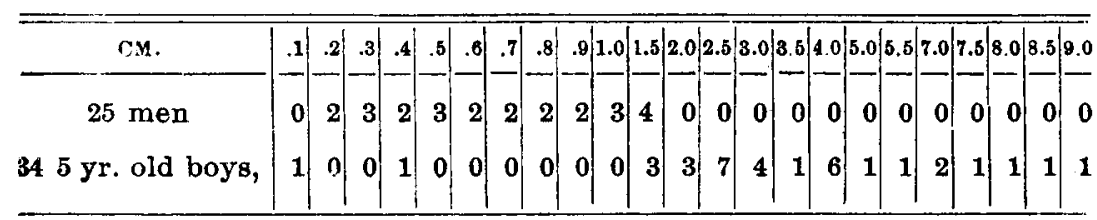

The chart shows the ranges for the finger.

Bryan $\left({ }^{6}\right)$ has shown that the rate of tapping for the child of sixteen is about five times as great as for one of six, and that hand power is later than arm power in developing, but gains and eventually surpasses the arm power. Taking the rectangles of the standing and finger tests, and the lateral measurements of the shoulder test, the ratio of control between man and a five-year-old child in the swaying test is as 1 to 4.1 ; for the shoulder, 1 to 4.5 ; for the finger, 1 to 5.8 . While these results may not stand with more extended research, the truth evidently lies in the direction they indicate; and, in my opinion, the motor control in man is from three to six times greater than that of children in the first year of school life.

The order of control is from fundamental to accessory, and is evidently in harmony with the theory of physiological development.

II.

The following results are from simple and general tests, and throw some light on the motor ability of children to make complex coördinations, both of larger muscles and of smaller ones.

A pattern found in most of the kindergarten guides consists of four slats interlaced. This was taken for a test, using slats eight inches long and one-half an inch wide. Four were taken and interlaced before the children, and left so for them to see; four others were then given to each child, and the children were asked to interlace them. The slats were interlaced a second or even a third time before the children, yet but one child-a girl of six-succeeded; nine copied the figure, the remaining fifty failed wholly. There was not opportunity to test more.

Test number twelve of the second series gave significant results; 162 children were tested with this, none of whom succeeded in reversing the movement; five succeeded somewhat slowly in tapping correctly with both hands; four were successful with the right hand only, and three with the left; fifty tapped with the whole hand, using a wrist motion ; nine with the whole hand, using an elbow motion; five with the 
whole hand, with both an elbow and a wrist motion; fortynine alternated the index finger with the other three; seven of these, however, did this with one hand only, the movement of the other being with all of the fingers moving together from the knuckles; twenty-five gave irregular movements indefinite and uncertain, but in many instances approaching success ; in twelve cases the movement was from the knuckles, all of the fingers moving together.

I am not concerned at present with the effect of training on the ability of children to make these movements, but rather with the problem, what is the period of the development of function in the nerve centers controlling the finer muscles concerned in delicate coördinations? Evidently for these children it is only beginning.

Fifty-six boys were asked to thread a large needle; fifty succeeded, but often only after two or three efforts; six failed, though given extra large needles and more time. It was evidently new to most of them. After the first trial there was in many cases apparent a feeling of nervousness.

Twenty-two out of sixty-three children failed in the effort to tie the ends of a two-foot string together. Those who succeeded tied, in every instance except four, the ends by placing them side by side. This is the simplest form in which it could be done.

In the tests for the coördination of the larger muscles, far less difficulty was experienced. The eleventh test of the second series bas often been tried by older people, and in some places by children. It was new to the children reported on here. The novelty first amused them, yet all but three asked, made an effort to get the movement. They were first asked to make one hand move in a circle on the breast; after this was started they were asked to place the other hand on top of the head and pat with it. In forty-five cases the result was either patting with both hands or moving them both in a circle. In the other ninety-seven cases there were first unsuccessful movements, often patting with both hands or moving both in a circle, or an alternating of these, but a considerable degree of success followed in each case.

One hundred and sixty were shown how to beat time. Arm movements were used. Practically all could beat double time freely. Treble and quadruple were more difficult, but by going slowly it was done by all but fifteen. Not more than two minutes' time was taken with each test; and it seems reasonable to suppose that, with ten or fifteen minutes' careful training, all could succeed.

Details of individual cases are of interest. something of the range, these three are given :

As showing 
M. is a girl of six years. She has now had about eight months' schooling, all told. Her teacher speaks of her as one of the brightest pupils. The rectangles for the swaying tests were $3 \mathrm{~cm}$. by $4.1 \mathrm{~cm}$., and $4.4 \mathrm{~cm}$. by $2.9 \mathrm{~cm}$. These are among the smallest. The lateral movements for the shoulder were $3.8 \mathrm{~cm}$. and $3.1 \mathrm{~cm}$. These were not so small as many others. For the finger the rectangles reduced were $.075 \mathrm{~cm}$. by $.05 \mathrm{~cm}$. and $.15 \mathrm{~cm}$. by $.05 \mathrm{~cm}$. Here again she is among the best. She could walk normally with the eyes closed. One finger trembled when she was tested for tremor; but she was quite free from all trace of tendency to chorea. In the tapping test she used a wrist movement for the whole hand, yet she was the only child who succeeded in interlacing four slats. She had no difficulty with any of the tests for the use or coördination of the larger muscles. Her general appearance is that of a healthy, intelligent child. B., a boy of five years, is one of the interesting cases at the other extreme from M. He is one of his teacher's "third best; bright as could be expected from him; not very good in his lessons, but not a bad boy." His results in the tirst test were $5 \mathrm{~cm}$. by $2.4 \mathrm{~cm}$. and $8.5 \mathrm{~cm}$. by $4 \mathrm{~cm}$. He so thoroughly lost his balance with eyes closed that he was caught to save a fall. The lateral measurements for the shoulder were $3.3 \mathrm{~cm}$. and $2.2 \mathrm{~cm}$. Here he did his best. The rectangles for the finger were, reduced, $.35 \mathrm{~cm}$. by .075 cm. and $1.2 \mathrm{~cm}$. by $1.4 \mathrm{~cm}$. He seems some stronger and brighter than his twin brother, yet the brother's measurements were some better. He shows decided tendencies to chorea, and is generally somewhat nervous. He can not speak distinctly, failing on $r, l, f, t h$, and $n g$. He failed wholly on the tests for finer movements, while in those for the larger movements, he succeeded only in beating time. A., B.'s sister, is six years old, and is one of ber teacher's "second best; she tries hard, but does not succeed so well as some." In the first test her measurements were $4 \mathrm{~cm}$. by $1.8 \mathrm{~cm}$. and 8.5 by $3.5 \mathrm{~cm}$. The lateral movements for the shoulder were 1.2 $\mathrm{cm}$. and $5.2 \mathrm{~cm}$. For the finger they were, reduced, $.35 \mathrm{~cm}$. by $.5 \mathrm{~cm}$. and $.525 \mathrm{~cm}$. by $.25 \mathrm{~cm}$. She also has strong tendencies to chorea. In the tests for the control of the finer movements, she was able to differentiate the control of the index finger; she could beat double time only, and failed wholly on test number eleven of the second series. She and her brother are Irish, plain looking, though not stupid, yet evidently not amongst the teacher's best.

The results thus far seem to justify the following inferences, though more extended research may change or modify them. 
Children early learn to make movements involving large muscles. They succeed easily in large movements of some degree of complexity. The order of development of control is, evidently, body, shoulder, arm, forearm and hand. In the hand control the index tinger differentiates before that of the others.

Fine and complicated movements are made with difficulty.

Efforts to keep quiet produce strong symptoms of nervous irritation. Movement is inhibited only in part and awkward swayings and twitchings result.

Children have far less control of their muscles than adults, as is shown in each of the tables

Generally the girl at the same age is steadier than the boy.

Children in normal healthy growth show a lack of coördination and control paralleled only by ataxic, choreic, and paralytic patients.

In support of this there were found thirty-eight, out of 150 , dragging the feet or walking with them wide apart when eyes were closed. The swayings of a very large number equal or exceed that of the ataxic patient. With test number four of the first series, in fifty cases there were twitchings and tremor in both directions. In twenty-six cases there were twitchings forward and backward only, and in twentyseven there were twitchings sideways only. Perhaps the twitchings were noticed more in the left hand, and there in the ring finger. Considerable care and practice are necessary to see and determine these. If this test is of value, apparatus for measuring and recording should be devised and used.

Sturgis' test for choreic tendencies showed that but half of 150 children tested were free from them. To show the importance of a knowledge of chorea and the value which Sturgis places on this test I give here his own statement : $\left({ }^{7}\right)$

"1. Movement disorder is the product and the index of mental disturbances, and may be known by nice observations of the higher muscles (the face and hands) before it has reached the stage to which the term St. Vitus' dance (or chorea) properly applies.

"2. When the school child (and especially girls between seven and twelve or thereabouts) alters in temper, works less well, less willingly than usual, gets untidy or slovenly, in a word, degenerates mentally and bodily, inquire of the mother as to home conduct and temper. Ask particularly how the child sleeps and whether she complains of headache or limbache and whether her food is sufficient.

"3. A mongst the incidents of school life apt to be injurious in the way we are considering, there stand out prominently 
examinations, moving into a higher class, sums (too difficult or ill explained), and punishment or admonition before fellows.

"4. The best index of muscular infirmity tending to St. Vitus' dance is the hand. Face mobility may be more nervousness, the tongue may be tremulous by nature. The hand test is infallible, and may be thus applied.

"Bid the child hold up both hands open, with extended arms, the palms towards you. If that is done steadily, both hands upright and both alike, no finger or hand quivering, no falling back of either hand, nothing to choose between the positions of the two, then the child has not nor is it near (either before or after) St. Vitus' dance. You may confirm this test by another. Let the child place the open hands upon yours, palm to palm. Look then at the backs of the child's hands, observe whether fingers or thumbs (especially the latter) repose without tremor and without restraint."

In the gradual acquisition of control of its muscles, the child needs to be carefully guarded from inconsiderate treatment. He should, if chorea seems at all imminent, be taken out of school, freed from responsibility and given for some weeks a quiet out-of-door life, with plenty of nourishing food and as much sleep as possible.

\section{III.}

It remains to consider briefly the principles of physiological development and certain pedagogical experiments in relation to the foregoing results :

Exercise is a term with a great variety of meaning. In its relation to education it is, to quote Du Bois-Reymond, $\left({ }^{8}\right)$ " the frequent repetition of more or less complicated action of the body with the coöperation of the mind, or of an action of the mind alone, for the purpose of being able to perform it better."

The close relation between muscle, nerve and mind makes it impossible for exercise to affect one alone. The various senses and powers of mind are all called into play to give proper adjustment to the muscles in all the range of activity from the play of the child to the work of the artist and artisan. Herein lie great possibilities of education. Motor centres make up about one-third of the brain. By motor training brain growth and mental activity are increased and new avenues are opened leading to a more intimate acquaintance with the world.

The laws of physical development should be regarded more in the construction of systems of education. Modern studies 
in physiology and anthropology have confirmed the theory of Spencer, which Ross $\left({ }^{9}\right)$ has formulated as follows: "The nervous system of man is at first similar to that possessed by all animals which possess a nervous system, or, at any rate, all of those which are sufficiently elevated to possess a spinal cord, but, as development proceeds, the nervous system of man becomes gradually differentiated from that of an ever increasing number of lower animals, while still maintaining a general likeness to the nervous system of the higher animals up to the time of birth. This, then, constitutes the fundamental portion of the nervous system of man; but after birth the accessory portion, which, up till this time, only appears in a rudimentary condition, now undergoes progressive development. It will thus be seen that the fundamental portion is first developed, and that the superaddition of the accessory portion greatly increases the multiformity, the complexity and the specialty of the human nervous system, and that it is the latest product of its evolution." These studies indicate further that each nerve centre has its period of growth and development of function. No careful study of this sequence has yet been published. Such a study would contribute a great deal to pedagogy. The proper exercise of the organs which each centre coördinates determines its development. If the centre is forced before its time, disorders of muscle and nerve control result. It is developing the limb of the tree before the trunk is strong enough rightly to sustain it. On the other hand, if the center is not properly exercised during the periods of growth, partial arrest results. "It is when growth activity, although becoming less energetic, and when functional activity, although still feeble, is gradually gathering strength, that most may be done to make or mar it, and other centres with which it is associated. Then it is that by suitable exercise and stimulation cautionsly applied, it may be brought to the highest development of which it is capable. By skillful management, this nascent period may be prolonged and a superior substratum provided for subsequent development; but by undue eagerness or neglect it may be curtailed or allowed to slip past unimproved. . . . . These facts, that cerebral centres never properly exercised do not develop, and that when once developed they are not so liable to waste on the withdrawal of their appropriate stimuli, or when they are cut off from their natural activities, strongly inculcate the importance of educating every centre at its nascent period, and the danger of postponing education till the nascent period is over." ( $\left.{ }^{10}\right)$ This opinion of Crichton-Brown is sustained also by the statement of a leading student of physical 
training in America. He says: "The defective exercise of any group of muscles during the growth period of its own particular centre will result not only in the dwarfing of that particular centre, but a corresponding weakness must exist in the whole mental fabric. . . . . Any system which substitutes training of the accessory neuro-muscular mechanism for that of the fundamental one, or which exacts undue work of the undeveloped accessory centres, or attempts their training out of the proper order of their ripening, is bound to contribute more toward the promotion of brain forcing than toward its prevention." (11)

In defective classes, faults are "written large." Experiments in training them give the opportunity to see results clearly. No class of defectives is more interesting to the student of pedagogy than idiots. Physical training has been carefully tried with them with the result that forty per cent. are lifted from the condition of helplessness and sent home really productive members of society. There is in their education no other way possible than through the medium of physical training.

As a concrete case of this training, that reported by $\mathbf{S}$. Seguin $\left({ }^{2}\right)$ in one of the last years of his life, is of great significance. When training was begun, the child, a boy of seven, was weak, walking with difficulty, unclean in habits and subject to fits of intense passion. Both hands and fingers were out of his control. He could will and execute, yet not with precision, only movements of elevation and abduction of the arm. The training of the hand for all of the various movements of which it is capable, was not possible, but the training of physiological aptitudes for them was. The value of these operations intellectually depends on their precision, unity, singleness or complexity. How to get the child to take notice of the teacher's movements, take an image of them, transmit the image, and will its execution in an accurate way and without interruption, was the problem. It was solved by giving exercises which involved the body first; these were succeeded in turn by those of the shoulder, arm, forearm, wrist, and hand, the more complex being brought in gradually and also constantly supplemented by exercise of the larger muscles. The hand was many times a day trained, either with or without the help of the senses, to act and feel, and to extend constantly with the range of its own operations that of the mind. The boy's health grew better. From being a burden, he learned to help himself, to amnse himself, to know the ordinary variations of temperature, water, food, etc.; to recognize and name about fifty things by their shape, and as many more by their texture. He acquired 
a love for flowers and took pleasure in caring for them. He became able to recognize and name thirty by their fragrance. His temper was better controlled, and his habits became cleanly. He learned the typical geometrical forms, and to cut them out of paper, and to measure and arrange objects according to their length.

Reading and writing, says the report, belong to a stage much in advance of this. A store of ideas, names, qualities and actions is to be first accumulated; the child is to be taught to write his own thoughts and then to read what he has written. "Rapid harmonization and filling up of the cranium, particularly in the lower frontal region," was one of the most noticeable results of the training. The five pictures of him at different stages certainly corroborate the statement.

The idiot has great difficulty to direct both eye and mind. Seguin used the hand to present objects to the eye in their proper relations. Imitation was his starting point. Emphasis was thrown on the index finger as a leader in directing the eye. Repetition followed imitation; analogy extended the use of the finger as care or need made necessary, while it was intellect. ualized by adding a meaning to each of its uses. "Sometimes his hand, oftener ours," says the doctor, "makes him look for, find out, glance and gaze at, watch, survey, select and follow ideal objects."

"Throughout, the motor training of this idiot followed the laws of physiological development; and the case gives remarkable evidence of the advantages of such education."

Equally interesting, yet dealing perhaps somewhat more with the advantages in general of physiological training, is the experiment of Dr. Wey with criminals. ( ${ }^{13}$ ) At the Elmira reformatory he experimented with a class of forty-three dullards, none of them mentally unsound, yet all incapable of prolonged mental exertion, and spasmodical and unsatisfac.tory in shop work. Twelve of the most indifferent were selected for the first experiment. All of these had been either common laborers, tramps, hostlers, or street loafers. Many had intemperate parents, one an insane, and another an epileptic, mother. They were given a special diet, were bathed three times a week. Passive exercises by a special trainer were given, as were more active ones to supplement the routine of shop work. Their mental attainments were of the lowest order. "One could neither read nor write, one could barely do either, four understood the successive steps in long division, but never could obtain the correct answer, while the balance came to grief upon the shoals of rudimentary arithmetic from notation to simple division. Their stock of 
jnformation was surprisingly small, being generally limited to a knowledge of the things they liked to eat and the work they preferred to do. Not one knew the name of the country in which he lived, its physical features, or the location of cities and states." Their ages ranged from nineteen to twenty-three. One was Irish, one Canadian, and the others American.

The physical training was of the kind used for idiots, " setting up exercises," marching, dumb-bells, etc.

School-room work was carried on in penmanship, reading, and mental arithmetic.

After five months, the experiment with this class was discontinued. All had improved physically, excepting one who died from pulmonary disease; the aimless shuffling gait had disappeared, as had much of the dull, stolid look. The average marks increased from 45.25 per cent. to 74.16 per cent. Under the system of marking, which admitted the earning of three marks during each month, in demeanor, labor, and school studies, it was possible for the eleven men to earn 594 marks in six months. In point of fact, they earned fifty-nine during the six months before the experiment. During the six months following the experiment, they earned 490. In the six months before training one man had stood $-25 \frac{5}{6}$, in the six months after training he stood +2. Another rose from a grade of one to a grade of two and two-thirds during the same periods; yet another, from sixteen per cent. to ninety-four per cent., also during the same periods. The first named sank from three to two and one-sixth in labor, yet rose from forty-six per cent. to ninety-four per cent. in his school studies. At the time of Dr. Wey's report, something over a year later, three of the men are marked as not doing well in demeanor, four are especially commended as making an honest effort to maintain their improvement, three others have earned their release on parole.

The remainder of the forty-three, though not so stupid and dull, were treated similarly and with similar results. This training did for these men what all of the appliances in what is perhaps the most progressive reformatory in the land failed to accomplish otherwise.

IV.

Much emphasis is thrown, in ordinary discussion, on the necessity of making directions exceedingly clear, to get children to do what is required of them. The student of children has it strongly impressed on him that the child ordinarily has very slight power of sustained attention, except in the 
lines of his spontaneous activities and interests, and that he cannot grasp anything in any great detail. His mental powers are very small. As Barnes has shown ( ${ }^{4}$ ), the child thinks in units fragmentary and broken. Such logic as it has is very poor. It is interesting to note that Hodge (15) found the curve of search in carrier pigeons, dogs and man logical, while that of children was illogical in the extreme. The activities and emotions are dominant in childhood, and yet we insist on training the intellect from the first primary year. Theory and fact unite in showing that mental growth can be best helped by proceeding on lines in harmony with the law of development. The application of this law should be made especially to all phases of motor training.

A few suggestions are offered: Physical training should constantly supplement manual training. Manual training should utilize the hammer and saw before the knife. Their use may begin very early. In the teets to be reported on, as tried by other teachers, I find the twenty children, all under five years, in the Worcester Normal School kindergarten, can not only start a nail, but drive it in the wood some distance : only one out of twenty failed, and this one has defective eyes.

Scriptare and Mason ( ${ }^{10}$ ) have shown that children draw most accurately vertical and horizontal lines. From some hundreds of specimens of children's first efforts in writing, I find the great majority make their down strokes vertical, or nearly so; where not vertical, the tendency is to slant them to the right slightly. This is in harmony with the WundtLamansky theory, that the eyes move more easily in vertical and horizontal directions. These facts support the movement in the schools toward vertical writing. Writing should be begun late, and then on blackboards, with a very great deal of practice with the whole arm. If it could be wholly black. board practice for several months, better still. Pages spaced are neither helpful nor necessary. Early writing on paper should all be large, and allow for the inability of children to conform exactly to demands for great accuracy.

I cannot see what elements there are in geometrical draw. ing to appeal to children. They are not capable of the great degree of accuracy and adjustment of fine muscles which it requires. Many of Barnes' conclusions in regard to drawing seem to be in harmony with the law of physiological development; and he rightly concludes that the grammur of drawing should come late.

Kindergarten work generally is too fine. Too great pre. cision, involving delicate and complex coördinations in pasting, weaving, folding, pricking and sewing, is insisted on Occupations and games for young children should be of a 
nature that will involve large muscles and movements. Certainly teachers may well give more assistance in the fine work, if they cannot see their way to make a change. They can, too, with greater frequency, permit games that are restful.

This paper can only be preliminary. Its results must be supplemented by much more extended investigations, that shall cover all grades of school life as well as home life.

Amongst the many to whom acknowledgments are due for encouragement, helpful criticism, and suggestion, are to be mentioned especially Drs. Hall, Burnham and Banford, also the Rev. Frs. Power and Griffin, Bupt. Marble, and the Worcester Board of Education for their courtesies in permitting tests in the Worcester schools.

I can not forbear to express also the obligation which in common with all others who have conducted investigations at this university, I am under to its founder for the exceptional facilities which his wisdom and generosity have here afforded.

Chart showing movement of index Anger in the effort to hold it still for half a minute.
a. Vertically $\} 25$ men.
b'. $\begin{aligned} & \text { Vertically } \\ & b^{\prime} .\end{aligned} 100$ children.

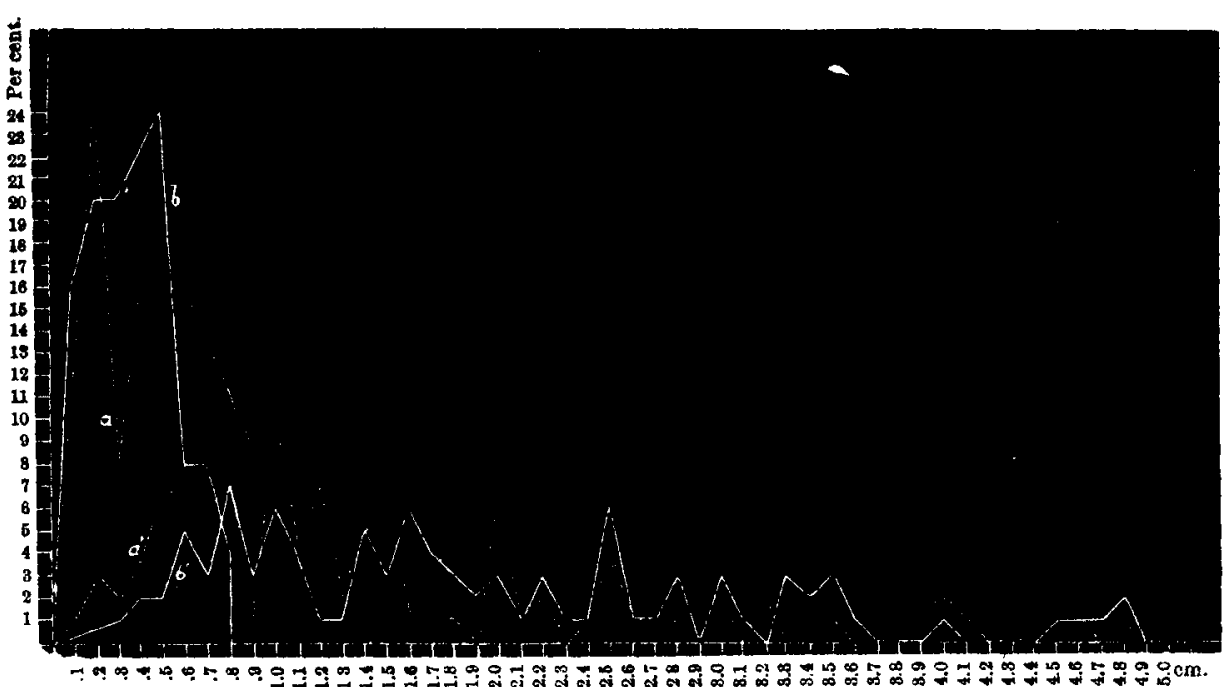




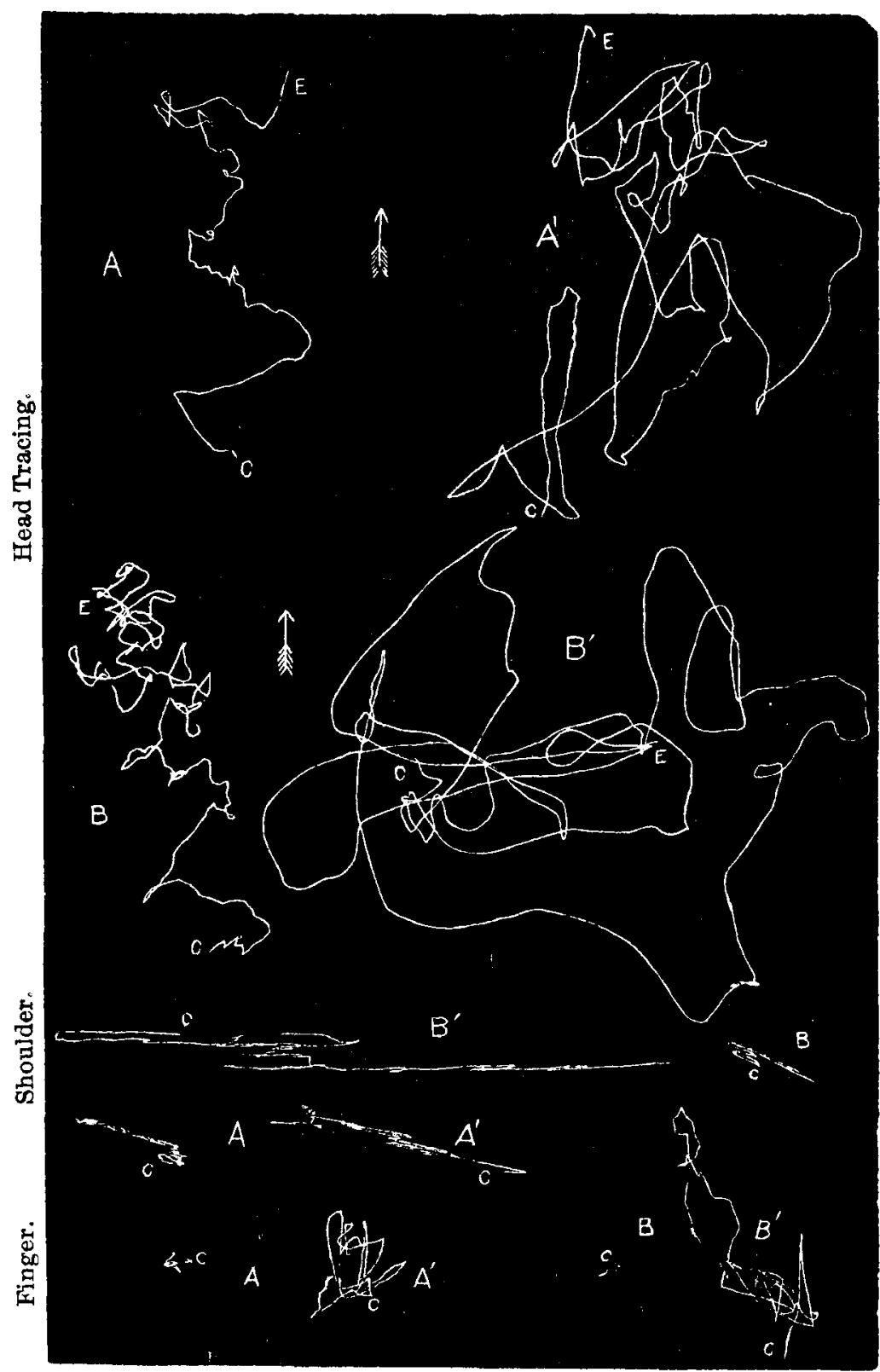

Specimen Tracings of Men and Children.

a, eyes open; b, eyes closed; c, point of commencing; e, of ending Arrow points back. 


\section{BIBLIOGRAPHY.}

REt.

Titer.

1. Dana. Text-Book of Nervous Diseases. p. 38.

2. Bullard AND BRACKetT. Boston Medical and Surgical Journal, Vol. II. of 1888. pp. 600-603. Also Vol. I. p. 136.

3. Hinsdale. The Station of Man. American Medical Journal, Vol. XCIII. pp. 478-485.

4. Jastrow. American Journal of Psychology, Vol. IV. p.

5. BULlaRD AND BRACKETT. Boston Medical and Surgical Journal, Vol. II. of 1888. p. 598.

6. BRyan. On the Development of Voluntary Motor Ability. American Journal of Psychology, Vol. V. No. 2.

7. STurgis. Report of Congress of Hygiene and Demography. London. Part IV. p. 20-27.

8. Du Bois-Reymond. The Physiology of Exercise. Popular Science Monthly, Vol. XXI.

9. Ross. Diseases of the Nervous System. p. 70.

10. Crichton-Brown. The Relation of the Nervous System to Education. Chap. IV. of Morris' Book of Health.

11. Hartwel. Physical Training Congress, 1889. pp. 16 and 18.

12. Sequin. Archives of Medicine. The Psycho-Physiological Training of an Idiotic Hand, Vol. II. The Psycho-Physiological Training of an Idiotic Eye, Vol. IV.

13. WEy. Physical and Industrial Training of Criminals.

14. Barnes. Children's Drawings. Pedagogical Swminary, Vol. II. No. 3

15. Hodge. The Homing Instinct in Pigeons. Popular Science Monthly, April, 1894.

16. Scripture and Mason. Yale Psychological Studies. p. 92-96. 